\title{
Co-option and Organisational Survival: A Case Study of the Risks and Opportunities of State Attachment within the United States Feminist Antiviolence Movement
}

\author{
Aisha Rios ${ }^{1 *}$
}

Published: March 19, 2018

\begin{abstract}
This article articulates the unstable and contested context of domestic violence advocacy and activism through the experiences of feminist antiviolence professionals working at a quasi-state agency in the southeastern United States. In the context of the NGOization of the antiviolence movement, this agency's attachment to the state created opportunities to insert marginalized perspectives into the dominant public dialogue on and responses to domestic violence but ultimately facilitated threats against the agency's entire existence. Organizational survival and a commitment to antiviolence advocacy at the state level led to resistance strategies against state cooption in alignment with neoliberal discourses and practices. State attachment in this context presented ambiguous outcomes for the promotion of feminist, survivor-centered goals, but strategic connections to community-based groups and the criminal justice system presented opportunities for effective resistance against state cooption.
\end{abstract}

Keywords: neoliberalism, antiviolence movement, feminist politics

\section{INTRODUCTION}

What are the risks and opportunities of attachment to the state ${ }^{1}$ for antiviolence professionals addressing domestic violence ${ }^{2}$ in the United States? Scholars and activists have described the co-option of social movements, by way of structural or economic state attachment, as one strategy used by states to govern and regulate political organising. The case study presented here contributes to this literature on governmentality and the co-option of social movements in the neoliberal era by highlighting the paradoxical effects of state attachment for professionals working within the antiviolence movement.

At the chosen research field site in the southeastern United States, the convergence of the Great American Recession between the late 2000s and early 2010s and an increasingly controlling politically conservative state governor's office set the stage for political attacks on a quasi-state antiviolence agency's existence in 2009. Increased surveillance by the state represented a change from a previous decade when this agency was more autonomous from the state and could implement a more proactive policy and legislative advocacy. In this article, I will draw an analytical distinction between state and quasi-state entities, the latter of which I use to characterise the agency, the Antiviolence Commission (AVC). ${ }^{3}$ The AVC was created in the late 1980 s by a southeastern state legislature and was administratively attached to the State Department of Corrections for its first several years. The agency was officially accountable to and reliant on the state for its legitimacy and authority to oversee statewide antiviolence work. Day-to-day operations entailed direct monitoring and governance over those intervening to address domestic violence at the county and city level. The staff struggled with and resisted identification with the state, while also leveraging certain conceptualisations of the state and neoliberalism to resist state co-option. I use the analytical

\footnotetext{
${ }^{1}$ I designate the state as that which holds "the monopoly of the legitimate use of physical force within a given territory" (Weber, 1965) and also functions as an apparatus of governance over its population.

${ }^{2}$ I use the term domestic violence to define physical, emotional or psychological, economic, and sexual abuse perpetuated between intimate partners. I also recognise the use of an array of other terms by scholars and practitioners alike, such as gender violence and intimate partner violence, and that the social construction and usage of these terms have fluctuating meanings for diverse people.

${ }^{3}$ All names of individuals and organisations are pseudonyms.
} 
framework of governmentality as a starting point to interrogate the AVC's routine operations and the reactive discursive survival tactics in response to the political attacks (Ferguson and Gupta, 2002; Foucault, 1980).

In this article, I argue it is not only everyday practices but also exceptional moments of resistance against state co-option where spatial and vertical imagery can be deployed by quasi-state entities to produce conceptualisations of authority and legitimacy. These events reveal the risks of state attachment that the literature illuminates for an agency formally integrated within the state apparatus. What are the implications for antiviolence work situated in formal organisations politically and economically reliant on the state for survival, and what opportunities are provided by this co-location? The case presented here suggests state attachment may be less perilous when antiviolence agencies are allied with community-based groups and others closely affiliated with the socially powerful criminal justice system.

\section{NEOLIBERALISM, THE CO-OPTION OF SOCIAL MOVEMENTS, AND THE STATE}

Scholars have critically examined the processes of neoliberalism ${ }^{4}$ revealing the state's strong presence in the lives of its citizens, in spite of the popular 'less government' rhetoric espoused by neoliberal proponents (Goode and Maskovsky, 2001; Hyatt, 2001). The neoliberal push towards self-regulation, self-management, and consumer 'choice' among privatised options has not constituted an absolute retreat from state governance entirely. Instead federal and state government is still firmly situated in a position of authority and control over an array of regulatory agents who enact governance over citizens, such as increased surveillance and regulation of the poor (Goode and Maskovsky, 2001; Websdale, 2001) and the promotion of civil society entities that provide the services for which the state has renounced responsibility (Hyatt, 2001; Rose, 1990). At the same time, macro-level neoliberal politicaleconomic policies have led to the scarce and uneven distribution of resources to NGOs in the United States. While NGOs have increasingly taken on the former role of the state as the provider of a socioeconomic safety net for marginalised communities, state allocation of resources to support this type of work has not been adequate. One route neoliberalism supports the governance of individual citizens at the state and non-state level, is by differentiating between those deserving and undeserving of particular services. Examples include social and legal conceptualisations of welfare dependency (Abramovitz, 1996; Cruikshank, 1995) and the construction of domestic violence survivors deserving and undeserving of social services (Allard, 2005; Lazarus-Black, 2007).

Scholars and activists have described the ways attachment to and reliance upon state funding creates pathways for state co-option beyond the outright surveillance and regulation of the population, which presents challenging paradoxes under the constraints of such a position. An extensive literature makes problematic the professionalisation of antiviolence advocacy and suggests in some cases this has come to represent the state cooption of political dissent (Kendrick, 1998; Markowitz and Tice, 2002; Schechter, 1982; Smith, 2007). Feminist organisations, while diverse in organisational ideology, goals, and structure, are one example of sites often governed by some form of state attachment, including legal incorporation and state funding (Martin, 1990). Susan Schechter (1982) offers an important early examination of the quest for increased funding within the antiviolence movement that led to the professionalisation and co-option by the state. Schechter vividly describes how advocacy within the movement gradually transformed from a volunteer to a paid position and how advocates became increasingly hesitant to challenge funders required a focus on services and measurable outcomes over social change goals. Another way the state co-option of social movements has been theorised centres on the transformational impact of state governance through NGO-isation. Madeline Adelman describes NGO-isation as 'the transformation of social movement activities from protest politics to policy work through the development and institutionalisation of social movement organisations (SMOs) - that is, NGOs that are tied politically and economically to the state' (2008: 512). While this term only came into popular use the last decade or so, Schechter's early work examined the processes of NGO-isation specific to the antiviolence movement.

When electing to formalise as organisations with access to socially and politically powerful actors connected with the state, professionals perceive their position as an opportunity to integrate marginalised perspectives into the policy arena and public dialogue with the hopes of shaping policy and programs (Reinelt, 1995). However, as Piven and Cloward's (1977) historical analysis suggests this is a flawed conceptualisation of the capacity of formal organisations to compel change in alignment with oppositional politics. Attachment to the state and the professionalisation it confers, may position antiviolence professionals in a way that organisational survival becomes inextricably tied to identity, that risks becoming a priority over more social justice oriented goals. This is particularly challenging in neoliberal contexts in which civic duty and volunteerism are understood as the most efficient route

\footnotetext{
${ }^{4}$ Neoliberalism represents a set of beliefs and practices characterised by the shift from the Keynesian welfare state to marketbased strategies to address social problems that have gained strength through the end of the $20^{\text {th }}$ century and into the 21 st. Self-regulation, self-management, and free market strategies are favoured over state provided social services in the name of individual responsibility and freedom (Harvey 2005).
} 
to ensure societal well-being and produce social change, although civic engagement does not exist outside the control of the state as touted in the public discourse (Hyatt, 2001). For instance, Uzwiak's (2013) ethnographic research at a women's human rights NGO in the United States demonstrates how the staffs' belief in human rights work as fundamentally good interacted with neoliberal modes of governmentality, including managerialism and self-governance, to deter staff from standing up against mistreatment. The redefinition of the citizen under neoliberalism as a volunteer responsible for the work that was formerly a state duty was the context in which NGO staff tolerated negative treatment rooted in a fear of jeopardising their organisational work on women's human rights. Uzwiak characterised this as an 'embodiment of fear,' tied to a commitment to social justice in conjunction with neoliberal governmentality, which produced a disconnection between political stances and organisational practices.

Other scholars have demonstrated that the state management of political action has more ambiguous effects than totalising conceptualisations of neoliberalism make the effects out to be. Sandra Morgen (1990) has shown that outcomes of state attempts at management and control of grassroots organising are not always clear-cut, and often have contradictory effects on its targets of control. Her work describes how a grassroots women's centre faced regulatory practices through the use of state funding, but that funding enabled the onboarding of new staff and eventually led to a resurgence of feminist ideology and goals. Reinelt (1995) shows how engagement with the state not only poses risks but opportunities as well, and Abraham and Tastsoglou (2016b) also argue that the state's involvement in addressing domestic violence offers opportunities for justice, though not without pressure from external social movement actors. An example of social movement actors effectively working with government agencies is presented by Arfaoui and Moghadam (2016) who present the case of Tunisian feminist social movement actors able to work with government to increase awareness of violence against women and institutionalise policy changes. However, even these legal reforms did not consistently reflect realities on the ground and social movement actors were faced with opposition broadening the scope of advocacy beyond gender to sexual rights.

It is clear the state is implicated in the production and condoning of a continuum of interpersonal and structural violence (Scheper-Hughes and Bourgeois 2005) through the promotion of particular ideologies and practices, particularly within the criminal justice system, that manifest in racialised and gendered forms of sexual violence (Goet,t 2015) and domestic violence (Adelman, 2008; INCITE!, 2006). However, as Abraham and Tastsoglou (2016a) suggests, the state's role in regulating gender and violence, as well as the antiviolence movement, varies by historical moment and context. Ferguson and Gupta (2002) make a valuable contribution to theorisations of the state by describing states governmentality as actioned through particular symbolic mechanisms and practices, showcasing state verticality and encompassment, to help to secure their legitimacy, to naturalise their authority, and to represent themselves as superior to, and encompassing of, other institutions and centres of power' (2002:982). At the same time, they challenge the dichotomisation of state and non-state entities, calling for an exploration of the processes through which actors situated within an ever-increasing assortment of state, non-state, and quasi-state entities utilise claims of verticality and encompassment as an instrument of governance. I later use this theoretical framing to examine the AVC's use of discursive tactics to asserting spatial and vertical superiority over other state bureaucracies and resist state co-option.

\section{METHODS}

For this case study, fieldwork took place in the southeastern United States working with the AVC staff and advisory board members, as well as with other antiviolence professionals connected to a larger network of domestic violence advocacy in the state. The field site is confidential in alignment with the consent process. ${ }^{5}$ Ethnographic data was collected between January 2009 and October 2010 through a combination of semi-structured interviews, participant observation, and archival research. ${ }^{6} \mathrm{I}$ interviewed a total of fifty-three antiviolence professionals working at the state and local level; however, in this article I focus on my interactions and interviews with the six AVC staff, four AVC advisory board members, the statewide Coalition of Domestic Violence Agencies (CDVA) ${ }^{7}$ executive director (ED) and lobbyist, one member of the state legislature, and a state-level bureaucrat who was also a former AVC member. Reviewing archival AVC documents strengthened my understanding of historical shifts in domestic violence policy, advocacy, and programming, and helped me interpret my observations in the field as reflective of long standing power struggles. Such documents included advisory board meeting minutes, protocols, and manuals that reveal AVC legislative and policy work and program development.

\footnotetext{
${ }^{5}$ This study was reviewed and approved for human subjects research by the Temple University Institutional Review Board. ${ }^{6}$ While these data were collected several years ago under a specific historical moment and the current political context has changed significantly, these findings are still relevant insofar as they suggest successful strategies to resist state co-option in the context of an increasingly hostile and conservative political environment.

${ }^{7}$ The CDVA provided policy advocacy and other support services for local shelters and other service providers in the state.
} 
My entry point into the field was the AVC whose staff granted me access to their day-to-day work and archival records. I spent the majority of my time at the AVC office working alongside the staff, attending meetings, trainings, and other advocacy events. In this role I interacted with a diverse range of antiviolence professionals working at the state and local level and observed what came to represent two years of political attacks on the AVC's existence. I was provided access to informal spaces of practice and dialogue, illuminating the value of participant observation as a methodology. Cultural immersion, the foundation of participant observation, supports access to these critical sites (Fife, 2005). Unfortunately, I was unable to interview most legislators and bureaucrats within the Governor's Office, who were aware of my connections with the AVC, as my communication requests were ignored. I was able to interview one legislator and another bureaucrat deeply entrenched in the political attacks; however, they were both long-time avid supporters of the AVC. Therefore, I was unable to collect data that spoke directly to the motivation behind attacks on the AVC.

Coordinating local and state practice was accomplished at the AVC through a variety of practices, including the employment of a Statewide Community Coalition Liaison to support coalition development and act as a liaison between coalitions and the state. I went into the field with the plan to focus on the work of and relationships between the AVC and community coalitions. I was curious about the form of governance the AVC exerted over community coalitions. While this was a key focus of my research, the political attacks on the AVC lasting throughout the duration of my fieldwork took centre stage in many ways, expanding my gaze to the legislature and Governor's Office. Additionally, while there were also clearly racial dynamics present across and within community coalitions, in this article I do not analyse these specifically at this time, but am instead focusing here primarily on gender.

\section{RESULTS}

\section{Education and Reform to Promote the Feminist, Survivor-Centred Agenda}

Education and reform activities conducted by the AVC reveal tensions between a feminist, survivor-centred ${ }^{8}$ analysis of domestic violence and depoliticised approaches to antiviolence work within the state. Providing a historical background on the AVC's intentional strategies to shape antiviolence practice and the interweaving power dynamics that constrain this work, foregrounds future challenges revealing the contested and unstable nature of their work. AVC staff and board members saw their formal position within state government and access to socially and politically powerful people as an opportunity to increase awareness of domestic violence across the state through a feminist, survivor-centred lens, but this was not without challenges.

The AVC was legislatively established with professionally diverse membership requirements to develop a coordinated statewide plan to end domestic violence. This plan included education and reform as a formal duty that in practice happened within a wide range of settings ranging from the very structured to the informal. Beyond formal education through the AVC's annual conference and other trainings, informal education efforts between AVC board members and staff was also a regular occurrence. In practice, the overall thrust of the informal education project centred on bringing a feminist, survivor-centred analysis to the attention of board members who were generally lacking such a perspective. A research subject shared a key goal of educating powerful judges and other criminal justice system representatives was to be able to send those newly educated, powerful representatives into public and private places of influence to transmit a feminist, survivor-centred perspective. Archival documents revealed the importance of a feminist analysis of domestic violence within the AVC's early work that was a key part of the staffs' analytical repertoires during my fieldwork. For example, meeting minutes from the AVC's second board meeting in early 1993 included an educational component in which speakers from three domestic violence shelters described domestic violence as the product of patriarchy, and articulated how societal norms and expectations about gender roles contributed to the oppression of women within and outside intimate relationships. The inclusion of an educational component helped establish a practice where the domestic violence advocate board representatives educated other board members on a feminist analysis of domestic violence even though the AVC was not explicitly a feminist organisation.

AVC staff and key board members participating in this informal education project juxtaposed with their own self-identified feminist lens against a board in which personnel were chiefly drawn from the criminal justice system.

\footnotetext{
${ }^{8}$ With an understanding that feminism has divergent meanings for different people, I define a feminist analysis of domestic violence in this particular context to take the identification of domestic violence as a product of patriarchy as central with an emphasis on survivor-centred approaches. Patriarchy refers to the institutionalisation of male authority over women and children within the organisation of the family and society, which holds gender is an important category of analysis. Survivorcentred practices prioritise survivors' experiences and knowledge, which includes trusting that they know their partners best and the most effective ways to stay safe. All of the AVC staff and key board members self-identified with this conceptualisation of feminism.
} 
All staff, along with two advocate representatives on the board adopted a feminist, survivor-centred perspective and took on the role of educating the board members from the criminal justice system representing over half of the advisory board. AVC staff and members understood that a heavy criminal justice system representation was beneficial to the agency's mission. Gary, an AVC staff person, shared a relevant example when he surmised that all of the AVC's board chairpersons after the first two were judges because having a judge's support lent credibility:

You know when the $[\mathrm{AVC}]$ comes to a decision to have a judge be a chair there's just more weight behind it system-wise...So ideally you've got an agenda that's being heavily influenced by the [executive] director with a feminist tilt but then a judge kind of once a decision is made putting some institutional weight behind it. I think that's an advantage the [AVC] has that the [CDVA] doesn't have. They [CDVA] make a decision that's backed up by people society thinks is low on the totem pole in general like shelter directors and advocates.

Gary made explicit the socially ascribed power judges held in contrast to domestic violence advocates and shelter directors, which validated the feminist orientation held by the AVC Executive Director and other staff. While not always effective, there were moments in which the positive effects of this education work were illuminated. For example, a superior court judge and AVC member shared a story marking an impactful moment during an interview. He attended an AVC annual conference in the early 1990s, and the AVC board chairperson at the time spoke critically about the way the media portrayed a domestic violence murder. The chairperson posed the question: why don't we ask why he's abusing her? Why do we always ask why she doesn't leave? The judge shared 'that hit me with a sledgehammer' and led him to think differently about domestic violence, no longer 'blaming the victim' for the violence. This story demonstrates how one board member (believed being on the receiving end of the AVC's education project) enhanced his understanding of domestic violence.

For the AVC, reform was a central, early goal, and the AVC was successful in proactively supporting legislative changes up through 2003, such as legislation prohibiting mutual protective orders and establishing a 24-hour centralised database for statewide protective orders. Starting in 2004, in partnership with the CDVA, the AVC began shifting its attention towards new targets of education and reform work through a fatality review project. The project aimed to identify missed opportunities to intervene in domestic violence cases and better equip systems with the tools to support survivors. This work demonstrated there were important sites beyond the criminal justice system and social services where survivors could receive support, including faith communities, friends, and family. Explicit statements in the fatality review reports identified intersectional ${ }^{9}$ inequities shaping the production of and responses to violence. Racism, homophobia, sexism, and classism were described as operating within the systems that respond to domestic violence, which hampered or deterred survivors from accessing support and resources.

\section{Unstable and Contested Context of Feminist, Survivor-Centred Antiviolence Work}

The AVC was legislatively created with term limits that ultimately showcased the unstable nature of its existence, which was exacerbated when the state increased interest in its activities. An increase in state surveillance signalled the beginning of attempts by the state to co-opt the AVC's antiviolence work which threatened to temper their feminist, survivor-centred agenda. Arguably, ideological differences within the statewide antiviolence advocacy community related to this agenda were leveraged by one of the state agencies threatening to co-opt the AVC as a tactic to consolidate their power.

When I asked Shannon during an interview why she felt the AVC struggled in recent years to pass proactive legislation, she argued the reason was 'the Republicans taking over in '05. That's truly the only explanation.' Shannon was the lobbyist for the CDVA ${ }^{10}$ and worked closely with Kelly, the AVC's Executive Director, on state legislative issues relevant to domestic violence. The AVC was legislatively charged with monitoring and evaluating domestic violence laws and policies, which represented a core part of their work. Shannon's retelling of the organisation's history represented a defensive approach to advocacy beginning when Republicans gained control of the state legislature and the Governor's Office with the election of Governor Payne. Kelly also underscored limitations due to the perceived Republican Party's power over the executive and legislative branch of state government. She shared a common understanding among her colleagues that an explicitly feminist orientation was less possible under Governor Payne compared to previous administrations. She explained:

\footnotetext{
${ }^{9}$ An intersectional analysis of domestic violence has been emphasised by scholars and activists as an alternative to individualising, criminalisation approaches and deemed critical for effective critical examination of the overlapping role of gender, race, ethnicity, sexuality, class, citizenship, and other social identities in shaping manifestations of and interventions in response to violence (Abraham and Tastsoglou 2016a; Crenshaw 1991; Sokoloff and Dupont 2005).

${ }^{10}$ There is a statewide coalition for domestic violence agencies in each state while the existence of a statewide commission was more distinctive. The AVC staff were aware of other similar commissions or councils operating within respective state governments. The existence of the AVC and other similar groups, many of which founded around the same time, reflected growing interest in the establishment of coordinated community responses since the first formal development of such a group in Duluth, Minnesota in 1981.
}

(C) 2018 by Author/s 
When I was hired that orientation [a feminist, survivor-centred approach] was tempered by an awareness of a particular political climate because of who the governor was and because he had inserted himself into the hiring process is my understanding of how that happened and that had never happened before I came on board. He never interviewed the previous directors but all of a sudden he was interviewing me.

Governor Payne's more active involvement in the AVC's hiring process foreshadowed the tenuous nature of their position attached to and dependent upon the state for funding.

While the AVC was convened by the State Governor's Office and relied upon state funding, which conferred the office with some power over the AVC's work, in practice the AVC operated independently of the Governor's Office up until a gubernatorial regime change in 2003. AVC board members and staff identified a major internal shift in AVC practice from proactive to reactive legislative and policy advocacy efforts at that time. This change was identified as a direct result of the politically conservative Governor Payne's entry into office, which became increasingly more 'hands on' over his two terms. AVC staff regularly discussed hesitancy to propose new legislation because they were afraid that 'opening up' legislation may result in losing existing political gains, whereas in previous years the AVC regularly proposed legislation each legislative session. Missy, an AVC board member and shelter advocate representative, broached the issue at a quarterly member meeting in December 2009 but the AVC chairperson, also a judge, rejected her idea due to the fiscal climate. Missy later expressed frustration with what she perceived to be a hesitancy to propose proactive legislation because of the hostile political climate during an interview.

Increased surveillance from the Governor's Office culminated in legislative attacks to eliminate the AVC in 2009, which eventually came to represent two years of political battles that echoed the historically unstable and contested nature of the AVC's existence. These events were situated in a political-economic environment in which the economic crisis allowed legislators to seek spending cuts. Suspicious tactics led up to the attacks, signalled by avoidance and rumour, including the Governor's Office staff evading Kelly's questions about renewing the AVC's term limits. The AVC was legislatively established with term limits that had to be renewed every four years which were set to expire in 2010. She queried the Governor's Office about this expiration multiple times to no avail. Finally, after much avoidance, in early 2009 when she learned statements calling for the eradication of the AVC was nestled within a two hundred-page bill restructuring the State Department of Human Resources (DHR). Assorted rumours swarmed throughout the legislature, including inflated figures for their state appropriations, number of staff, and inaccurate claims their work was a duplication of services.

The AVC never received any straightforward explanation for its proposed elimination beyond it being a cost saving measure for the state. AVC staff interpreted these tactics as a strategy to veil the state co-option of the AVC's work because the DHR restructuring bill was widely accepted as necessary. The effect would mean the elimination of the AVC, including its staff and volunteer advisory board, and diverting only two of its fifteen statutory powers and duties to DHR. A second political attack attempting to co-opt the AVC occurred the next year during the 2010 legislative session. These events threatened to move four of the seven staff positions to yet another state agency, the Governor's Office for Child Welfare (GOCW), and effectively dissolve the AVC through consolidation. The AVC was concerned about the proposed move due to perceived ideological differences, one strategy the GOCW ED, Jane, who was employed to gain the support of shelter directors was to promise they would not be forced to address race, sexuality, or other 'political' issues if she were in charge. This was a successful strategy in manipulating ideological differences within the antiviolence community. Gary describes this depoliticising strategy:

I think a lot of this has to do with Jane saying I'm not going to talk about pro-choice stuff, I'm not gonna talk about racism. We're just gonna talk about victims- helping victims. We're not gonna talk about any oppressions and all these lesbians coming around. Everybody's the same...So I think a lot of that was motivated by racism, sexism, and homophobia.

Jane took advantage of the fact that some shelter EDs were resistant to talking about gender, race, and sexuality, which further validated the AVC's concern about the proposal to move the AVC's duties into the GOCW. Ultimately, this argument was not enough to sway most EDs but did compel some to relinquish their organisational membership at the CDVA, which was perceived by some to be a radical, feminist organisation. These events added ideological differences to accompany the other political and economic arguments for the GOCW's consolidation of power.

\section{Resisting State Co-option}

The AVC strategically characterised themselves as a state agency with the attributes of a community-based organisation, while leveraging neoliberal discourses on volunteerism, in order to successfully resist state co-option. Public resistance tactics included calling on constituents to contact their legislators aimed to correct the spread of false information about the agency. The AVC staff sent out mass email messages with speaking points, legislative updates, and calls to action. A major hurdle the AVC faced was that many legislators lacked basic knowledge about 
the agency, which facilitated the spread of inaccurate information. In practice, the AVC operated as below the radar as possible during Governor Payne's two terms in order to avoid drawing attention to the agency rooted in concern they would be attacked in one form or another, similar to their hesitancy to propose legislation during this time. This may have inadvertently contributed to legislators' lack of familiarity with the agency.

Kelly lobbied at the Capitol nearly every day throughout the 2009 legislative session, which placed an inordinate amount of stress on her and the staff. Kelly witnessed inequities within the capitol firsthand. Leadership within the legislature was predominately white men, which did not reflect the composition of the state population and was problematic in a setting where committee chairs possessed enormous power over which bills were heard and emerge out of committee. Sexual harassment was widespread, and Kelly described interactions between male legislators and female lobbyists as disturbing. Men represented the vast majority of state legislators, which stood in stark contrast to their actual demographic composition within the state. ${ }^{11}$ The racial and ethnic composition of the state legislature was also not representative of the population. ${ }^{12}$

A public legislative hearing on the House bill eliminating the AVC was a pivotal moment. One call to action was attending this hearing to speak on the AVC's behalf. Eleven speakers were strategically selected by AVC staff and board members in order to present a justification for their existence. Taken as a whole, the arguments demonstrated a creative use of scale and spatial imagery to validate the AVC's role. The AVC was described as the only state agency with a statewide plan to end domestic violence and was 'unique' due to a diverse advisory board composition representative of a range of city and county-level perspectives. A white male speaker, self-identified as a former perpetrator, referred to the AVC as a 'watchdog of the state.' He argued the AVC's surveillance of domestic violence policies and practices across the state validated its high reaching authority. Multiple speakers presented the AVC as a critical source of support for 'local communities' and described how AVC staff supported antiviolence work over the years. The AVC was also represented as a community organisation in its own right because board members represented different localities. The Executive Director of a domestic violence advocacy organisation for Latino communities, argued that much of the AVC's work was performed by volunteers who represented 'community members,' which she proposed sent the message that 'the community' is responsible for antiviolence work. Moving the AVC's functions to DHR would transmit the message that this work was the state's responsibility and would lead to greater fiscal responsibilities for the state.

Another tactic to demonstrate the AVC's value was to highlight their capacity to leverage volunteer labour through its advisory board and one staff position. Early in the legislative session Kelly asked Jess, the AVC Community Coalition Liaison, to send an email survey to all of the community coalition chairpersons across the state to document the number of volunteer hours members spent collectively on their work. Kelly aimed to quantify the 'free' labour Jess' one position was able to leverage, which appealed to neoliberal ideologies promoting volunteerism and a smaller, more flexible work force. This approach reflected an overall focus on the bureaucratic procedure of demonstrating 'measurable outcomes,' which showcased efficiency and cost savings by stretching the state dollar. Highlighting the AVC's work as 'free' volunteer labour in opposition to the notion of big government was an interesting discursive strategy when the AVC's entire existence was predicated upon their being a state agency.

Strategies to fight elimination represented a multi-pronged approach to legislative advocacy that showcased the AVC's value as a quasi-state agency with the attributes of a community organisation. The statewide response to the AVC's legislative calls to action was heard loud and clear as legislators were bombarded with calls, emails, and in-person visits. Kelly and Shannon heard legislators felt compelled by the response to support the AVC. Together they lobbied for a new House bill eliminating the AVC's term legislation and extending its life indefinitely, which ultimately died in the Senate Rules committee, but they were ultimately able to modify the language in the original DHR reorganisation bill to achieve a similar effect. These strategies were effective and the AVC was able to forestall eradication. ${ }^{13}$

\section{Questioning State Attachment}

In the midst of these struggles, the AVC staff increasingly questioned their attachment to the state, which they associated with institutions of power that participated in the governance of its citizens through both formal structures of the government and informal modes of governance deployed to monitor, regulate, and control populations. They spent a great deal of time during staff meetings and informal conversations discussing their formal role as a state agency and passionately differentiating themselves from other state bureaucracies. Two of their program activities that were a source of trepidation were their monitoring work over community coalitions

\footnotetext{
${ }^{11}$ In 2010 women represented only $19.1 \%$ of the state legislators versus $51.2 \%$ of the state population.

${ }^{12}$ In 2009 the state legislature was 22\% African American versus 30\% of the state population and 1\% Latino versus $8.8 \%$ of the state population.

${ }^{13}$ The second round of attacks in 2010 required a different set of the resistance strategies that were also effective and are detailed in the author's dissertation.
} 
and batterer intervention programs (BIPs). ${ }^{14}$ As the staff sorted through these feelings, they reasserted the spatialisation of government of the state from above, highlighting the disconnectedness from the local and critiquing state actors' lack of knowledge of what is happening 'on the ground'.

While the AVC staff was uncomfortable with their role as a governing entity, historically the AVC did take actions to support, monitor, and direct antiviolence practice, particularly through their work with community coalitions and BIPs. For example, Jess was viewed as an authority on community coalitions and substantiated her expertise through the distribution of particular recommendations and resources. At the same time, through her interactions with community coalitions she used explicit strategies to resist a dictatorial image as herself as an agent of the state. She declared the diversity of localities across the state, and argued their organisational goals and structure should be reflective of this diversity. She joked about and directly rejected her authority over community coalitions during regular interactions. A push and pull between structured advice and qualifying authority was characteristic of Jess' approach. Her assertion of difference from the state represented an act of resistance in a context where her professional responsibilities included a governing role over community coalitions.

Staff had critical discussions about state sanctioned structural violence and structural inequalities embedded in the criminal justice system, which undergirded their trepidations regarding their role. A key area of the AVC's work that staff interrogated was their regulatory work over local actors and their embeddedness in the criminal justice system vis-à-vis the training, certification, and monitoring of BIPs. Amy, the AVC BIP Coordinator, questioned whether social change was possible when working through oppressive structures that produced and exacerbated social inequalities. While Amy problematised her participation in the BIP work and simultaneously her culpability in the regulation and surveillance of perpetrators, she felt constrained by her job requirements and statutorily defined rules for BIP certification. Even so, Amy believed their work did help to produce positive changes that improved safety for survivors and held perpetrators accountable.

The AVC staff struggled with their role but also harnessed imaginings of the state and aligned with neoliberal values through their survival tactics. This response was grounded in a fear of elimination and commitment to antiviolence work, which was not surprising given their precarious existence as demonstrated historically by their continued need to demonstrate their value. After two years of battles, the AVC was able dodge state co-option, but much time and energy was allocated to survival. This was so much so that they had to cancel their 2009 annual conference due to time limitations. Speculative conversations about why the AVC was under attack dominated day-to-day staff conversations and everyday practices were infused with resistance tactics that kept the struggle at the forefront of their minds. If Kelly asked the staff to create or review an email for distribution concerning the legislation battles, everyday work was temporarily put on hold to complete the task. There was a palpable sense of urgency in these requests. The staff was under an enormous amount of stress, not knowing if the AVC and their jobs along with it would be eliminated. By the end of 2010, four of the seven long-time staff voluntarily left their positions at the AVC, including the Executive Director, and the majority of long-standing board members were swapped out for new appointees.

\section{DISCUSSION}

Just as the state secures its authority and legitimacy through invoking and reproducing images of verticality and spatial encompassment (Ferguson and Gupta 2002), the AVC appropriated these powerful claims and produced a similar effect. The linguistic strategy of identifying the AVC as a community organisation invoked neoliberal ideologies that praised civic participation and a reduction of big government (Goode and Maskovsky 2001; Hyatt 2001). Martin (1990) also illuminates how conceptualisations of state power can be co-opted in order to fight injustices. Speakers at the hearing characterised the fact that the AVC was the only state agency committed to addressing domestic violence but characterised it as a unique, quasi-state agency because of the community representation and volunteer labour leveraged by it. By arguing antiviolence work belonged to the community not the state, there was an argument for the preservation of the AVC's volunteer advisory board. The AVC's capacity to claim such bilocality, as of and simultaneously below the state, reveals the socially constructed nature of the state and the community as sites of political action and sometimes opposition.

The tenuousness of the AVC's position calls into question the viability of feminist, social movement actors incorporated into formal institutions of state power, or indeed, that are state funded and therefore accountable to the state for their existence. While not an NGO, the AVC experienced similar paradoxes and constraints on their work compared with NGOs formally attached to and economically dependent on the state. AVC board members and staff were increasingly hesitant to propose legislation under Governor Payne's reign because they were afraid that doing so might open themselves up to losing past legislative successes. One way of interpreting this response

\footnotetext{
${ }^{14}$ Batterer Intervention Programs are a court-ordered program designed to rehabilitate perpetrators of domestic violence. The
} programs typically prioritise both the safety of survivors and holding perpetrators accountable for their abusive behaviour. 
is through Uzwiak's (2013) 'embodiment of fear' framework, which describes how fear of jeopardising organisational work sometimes leads to decisions in opposition to ideological perspectives. Similarly, the AVC's commitment to their continued positioning as a state agency working with formal state structures to influence antiviolence practice across the state dissuaded them from proactive legislative advocacy grounded in fear they might lose their position. The problems posed by the NGO-isation of the United States antiviolence movement hold true at this site as well. Markowitz and Tice (2002) present a vexing conceptualisation of such paradoxes that raised important questions that helped frame my analysis. They posited that while feminist activists efforts to professionalise organisations have successfully enabled 'once marginal feminist voices to be heard in established centre of political power...such efforts have frequently contributed to the persistence or creation of social hierarchies within and between women's organisations, as well as a subversion-or more generously-a reorientation of social change agendas and strategies' (954). The AVC staff contemplated this and wondered if it was possible to produce positive social change by working 'through the system' without reorienting dominant social change agendas.

The AVC staffs' internal struggle with their state alignment speaks to the challenges of antiviolence work in the United States neoliberal context, and is exacerbated when coupled with the attempted silencing of race, gender, and sexuality within the broader anti-violence community. They willingly engaged with what Reinelt (1995) identifies as the 'politics of engagement,' which is tied to a belief in their ability to institutionalise changes in policy vis-à-vis their state attachment. This was envisioned not only through legislative advocacy work but also through education projects targeting a wide range of systems to reform popular understandings of domestic violence. The perception that everyone is equally at risk of experiencing domestic violence was a powerful notion permeating across a range of settings. Across a diverse network of domestic violence advocates and other professionals, the erasure of difference happened through the use of the label 'political' and an argument that all survivors' experiences were the same couched in 'discourses of equality'. The ways race, gender, sexual orientation, and class differentially impacts the experiences of survivors and perpetrators was deemed irrelevant and furthermore, too 'political'.

Scholars have addressed the dangers of claiming equality as a political strategy (Minker and Snider, 2006; Richie, 2000). Jane leveraged this construction of domestic violence by arguing issues related to race, sexuality, and other 'political' issues could be ignored if she were in charge of the AVC's and CDVA's duties. She used this tactic to sway shelter EDs to switch sides, which made combating her agency's attempts at co-opting the work of both agencies all the more challenging. Sociologist and African American Studies scholar Beth Richie (2000) has dealt with the prominent expression in outreach and education work in the U. S. antiviolence movement, 'it can happen to anyone', which represents an effort by activists to deter the individualisation of the problem among the general public. Richie argues the popularity of this truism has led to the erasure of race and class as meaningful analytic categories and produces a problematic emphasis on white, middle-class women as 'deserving' victims. Sociologists Minaker and Snider (2006) have examined the growth of gender-neutral analyses in public and scholarly attention to husbands as domestic violence victims in Canada, which has become a new 'common sense' (755). This understanding of domestic violence is substantiated by 'discourses of equality,' namely the socio-political preoccupation with declaring the false claim of equality in male and female experiences of domestic violence, which functions to conceal inequities. In fact, according to the 2011 United States National Intimate Partner and Sexual Violence Survey, lifetime and 12-month prevalence estimates for intimate partner violence, sexual violence, and stalking are higher for women than men (Breiding at al., 2011). I identify 'discourses of equality' as a tool used to erase difference and depoliticise the issue of domestic violence, in turn hampering the AVC's resistance tactics against state co-option.

Following Markowitz and Tice, did the AVC's reliance upon the state for funding and ultimate resistance tactics in the face of political attacks produce a 'reorientation of social change agendas and strategies'? The AVC's entanglements with Governor Payne's Office certainly allocated much time to fighting for survival, and the ultimate departure of over half of the AVC staff and all long-standing board members produced a loss of institutional knowledge. However, the agency was ultimately successful in avoiding state co-option, it still exists today, and was able to host their conference in 2010 and subsequent years since then. Proactive legislative and policy advocacy were clearly tempered during the years under Governor Payne's tenure, but for years preceding the attacks the AVC successfully advocated for changes to improve the implementation of laws and policies, and reform criminal justice system responses to domestic violence. As Goett's (2015) ethnographic research suggests, the limits of legal reform to address domestic violence are that such an approach favours controlling and criminalising marginalised communities, instead of pursuing more comprehensive strategies that are attentive to the intersectional inequities that produce and condone interpersonal and structural violence. With that said, the AVC was able to expand their focus while Governor Payne was in office, by establishing the fatality review project, grounded in an understanding that a focus on criminal and legal reform left out other important sites where routes to justice and safety might be achieved. This work did not directly challenge the dominant criminalisation and social service provision response 
model in the state, but complemented it through a more holistic approach to interventions. The AVC was able to continue the fatality review project each year during the political attacks and annually since that time, raising attention to an intersectional analysis of domestic violence among its board members and representatives from various systems to present opportunities for system changes. These shifts provide evidence the AVC's education project was not derailed.

\section{CONCLUSION}

While the unstable and contested context of feminist, antiviolence work attached to the state at my field site is clear, so was the AVC's capacity to co-opt discourses of power and authority leveraged by the state in order to resist a more robust state co-option. The AVC staff and board members were successful in institutionalising changes over the first ten years of their existence that improved system responses to domestic violence, although not always as successful as they would hope. The consensus amongst AVC staff and board members was they had much more work to do and while an uphill battle, if they were co-opted or consolidated more fully under a different state agency, outcomes for those impacted by domestic violence would surely be worse. The political attacks, while ultimately unsuccessful, illuminate the trappings of political and economic attachment to the state and the insidious ways barriers to social change are structured.

Although many scholars and activists have demonstrated the negative ramifications of professionalisation and the increased interconnectedness and reliance upon the state by NGOs, others highlight possibilities and benefits. For example, Markowitz and Tice (2002) describe the ways in which professionalisation has created space for marginalised voices representing social justice movements within sites of political power. Abraham and Tastsoglou (2016b) identify education as an opportunity conferred by the state's involvement in antiviolence work, which should focus on deconstructing essentialist understandings of social groups and making visible inequality and discrimination, including the state's role in perpetuating it. While Abraham and Tastsoglou identify opportunities available through the state's participation in antiviolence work, they also argue there is a need for more communitybased efforts grounded in informal social support networks to compliment state investments. In fact, they argue such an education project will only be successful if there is continuous pressure from social movement actors.

Events in this case study have illustrated how there are opportunities presented by collaboration between statebased and community-level groups. These opportunities were illuminated when community coalition members lobbied on the AVC's behalf in response to the political attacks. Another way the AVC's relationship with community coalitions supported their ability to resist state co-option was when neoliberal ideologies lauding volunteerism were invoked based on the 'free' volunteer labour the AVC leveraged through community coalitions, which effectively represented the AVC as the antithesis of big government. Finally, the AVC's strategic inclusion of socially powerful criminal justice system representatives on its board, which was a recommended model for community coalitions, gave weight to their resistance strategies and education work more broadly. The present case suggests that structural attachment and economic dependence on the state presents risks of state co-option for an antiviolence agency; however, there are opportunities to oppose state co-option when leveraging spatial and vertical discourses of authority and legitimacy in conjunction with leveraging strategic connections to communitylevel groups.

\section{REFERENCES}

Abraham, M. and Tastsoglou, E. (2016a). Interrogating Gender, Violence, and the State in National and Transnational Contexts: Framing the Issues. Current Sociology Monograph, 64(4), 517-534. https://doi.org/10.1177/0011392116638843

Abraham, M. and Tastsoglou, E. (2016b). Addressing Domestic Violence in Canada and the United States: The Uneasy Co-Habitation of Women and the State. Current Sociology Monograph, 64(4), 568-585. https://doi.org/10.1177/0011392116639221

Abramovitz, M. (1996). Regulating the Lives of Women: Social Welfare Policy from Colonial Times to the Present. Boston: South End Press.

Adelman, M. (2004). The Battering State: Towards a Political Economy of Domestic Violence. Journal of Poverty, 8(3), 45-64. https://doi.org/10.1300/J134v08n03_03

Adelman, M. (2008). The "Culture" of the Global Anti-Gender Violence Social Movement. American Anthropologist, 110(4), 511-514. https://doi.org/10.1111/j.1548-1433.2008.00085_2.x

Arfaoui, K. and Valentine M. M. (2016). Violence Against Women and Tunisian Feminism: Advocacy, Policy, and Politics in an Arab Context. Current Sociology Monograph, 64(4), 637-653. https://doi.org/10.1177/0011392116640481 
Allard, S. A. (2004). Rethinking Battered Woman Syndrome: A Black Feminist Perspective, in N. J. Sokoloff (ed.), Domestic Violence at the Margins: Readings of Race, Class, Gender, and Culture (pp. 194-205). New Brunswick: Rutgers University Press.

Breiding, M. J., Smith, S. G., Basile, K. C., Walters, M. L., Chen, J. and Merrick, M. T. (2014). Prevalence and Characteristics of Sexual Violence, Stalking, and Intimate Partner Violence Victimization - National Intimate Partner and Sexual Violence Survey, United States, 2011. MMWR 63 (SS08), 1-18.

Crenshaw, K. W. (1994). Mapping the Margins: Intersectionality, Identity Politics, and Violence Against Women of Color, in M. A. Fineman and R. Mykitiuk (eds), The Public Nature of Private Violence (pp. 93-118). New York: Routledge.

Cruikshank, B. (1994). Revolutions within: Self-government and Self-esteem, in A. Barry, T. Osborne, and N. Rose (eds.), Foucault and Political Reason: Liberalism, Neo-liberalism and Rationalities of Government, (pp. 231-251). Chicago: University of Chicago Press.

Ferguson, J. and Gupta A. (2002). Spatializing States: Toward an Ethnography of Neoliberal Governmentality. American Ethnologist, 29(4), 981-1002. https:/ / doi.org/10.1525/ae.2002.29.4.981

Foucault, M. (1980). Power/Knowledge. C. Gordon, (ed.). Trans. C. Gordon, L. Marshall, J. Mepham, and K. Soper. New York: Pantheon.

Goett, J. (2015). Securing Social Difference: Militarization and Sexual Violence in an Afro-Nicaraguan Community. American Ethnologist, 42(3), 475-489. https:/ / doi.org/10.1111/amet.12142

Goode, J. and Maskovsky J. (2001). Introduction, in J. Goode and J. Maskovsky (eds.), The New Poverty Studies: The Ethnography of Power, Politics, and Impoverished People in the United States, (pp. 1-34). New York: New York University Press. https://doi.org/10.7312/godo11784-intro

Hyatt, S. B. (2001). From Citizen to Volunteer: Neoliberal Governance and the Erasure of Poverty, in J. Goode and J. Maskovsky (eds), The New Poverty Studies: The Ethnography of Power, Politics, and Impoverished People in the United States, (pp. 201-235). New York: New York University Press.

Incite! (2006). The Color of Violence: The Incite! Anthology. Cambridge: South End Press.

Kendrick, K. (1998) Producing the Battered Woman: Shelter Politics and the Power of the Feminist Voice, in N. A. Naples (ed.), Community Activism and Feminist Politics: Organizing Across Race, Class, and Gender, (pp. 151-173). London: Routledge.

Lazarus-Black, M. (2007). Everyday Harm: Domestic Violence, Court Rites, and Cultures of Reconciliation. Urbana: University of Illinois Press.

Markowitz, L. and Tice, K. W. (2001). Paradoxes of Professionalization: Parallel Dilemmas in Women's Organizations in the Americas. Gender and Society, 16(6), 941-958. https://doi.org/10.1177/089124302237896

Martin, P. Y. (1990). Rethinking Feminist Organizations. Gender and Society, 4(2), $182-206$. https://doi.org/10.1177/089124390004002004

Piven, F. F. and Cloward, R. A. (1977). Poor People's Movements: Why They Succeed, How They Fail. New York: Vintage Books.

Reinelt, C. (1995). Moving onto the Terrain of the State: The Battered Women's Movement and the Politics of Engagement, in M. M. Ferree and P. Y. Martin (eds.), Feminist Organizations: Harvest of the Women's Movement, (pp. 84-104). Philadelphia: Temple University Press.

Richie, B. (2000). A Black Feminist Reflection on the Antiviolence Movement. Signs, 25(4), 133-137. https://doi.org/10.1086/495533

Rose, N. (1990). Governing the Soul: The Shaping of the Private Self. London: Routledge.

Schechter, S. (1982). Women and Male Violence: The Visions and Struggles of the Battered Women's Movement. Boston: South End Press.

Scheper-Hughes, N. and Bourgois B. (2004). Introduction: Making Sense of Violence, in N. Scheper-Hughes and P. Bourgois (eds.), Violence in War and Peace: An Anthology, (pp. 1-31). Malden, MA: Blackwell.

Smith, A. (2007). Introduction: The Revolution Will Not Be Funded, in Incite! Women of Color Against Violence (ed), The Revolution Will Not Be Funded: Beyond the Non-Profit Industrial Complex, (pp. 1-18). Cambridge: South End Press.

Sokoloff, N. J. and Dupont I. (2005). Domestic Violence: Examining the Intersections of Race, Class, and Gender - An Introduction, in N. J. Sokoloff (ed.), Domestic Violence at the Margins: Readings of Race, Class, Gender, and Culture, (pp. 1-13). New Brunswick: Rutgers University Press.

Uzwiak, B. (2013). (2013). Fracturing Feminism: Activist Research and Ethics in a Women's Human Rights NGO, in C. Craven and C. Ain-Davis, (eds), Feminist Activist Ethnography: Counterpoints to Neoliberalism in North America, (pp. 119-136). Lanham, Maryland: Lexington Books.

Websdale, N. (2001). Policing the Poor: From Slave Plantation to Public Housing. Boston: Northeastern University Press. Weber, M. (1965). Politics as Vocation. Philadelphia: Fortress Press. 
Citation: Rios, A. (2018). Co-option and Organisational Survival: A Case Study of the Risks and Opportunities of State Attachment within the United States Feminist Antiviolence Movement. Feminist Encounters: A Journal of Critical Studies in Culture and Politics, 2(1), 04. https://doi.org/10.20897/femenc.201804

Copyright (c) 2018 by Author/s and Licensed by Lectito BV, Netherlands. This is an open access article distributed under the Creative Commons Attribution License which permits unrestricted use, distribution, and reproduction in any medium, provided the original work is properly cited. 